\title{
Gestão da Informação em Portugal: formação, mercado e perspectivas
}

Maria Cristina Vieira de Freitas, Maria da Graça de Melo Simões

\begin{abstract}
Resumo
As professoras Cristina Freitas e Maria da Graça Simões respondem questões elaboradas pelos docentes da Faculdade de Informação e Comunicação (Curso de Gestão da Informação) da Universidade Federal de Goiás - UFG. As perguntas se referem à estrutura de ensino voltada aos temas de gestão da informação em Portugal, a influência do fenômeno do "Big Data" na formação na área - incluindo discussões sobre a governança de dados, as áreas estruturantes da Gestão da Informação e enfoques de pesquisa no Pais, e as condições de mercado (ameaças e oportunidades) para os profissionais em Gestão da Informação em Portugal e no continente europeu.[Idioma disponivel: português/Portugal].
\end{abstract}

Palavras-chave

Gestão da Informação. Mercado de trabalho. Formação profissional.

\section{Como se constitui a estrutura de ensino voltada para a Gestão da Informação em Portugal?}

Em primeiro lugar, é preciso dizer que o conceito de Gestão da informação é, pela sua própria natureza, polissémico. Tal circunstância advém do facto de esta área comungar dos conceitos de pelo menos duas outras áreas que seriam naturalmente a Gestão e a Ciência da Informação. Esta particularidade concorre para que o conceito em apreço seja caracterizado por uma grande abrangência semântica, sob o qual muitos outros temas ou subtemas poderão ser tratados. É precisamente neste sentido que dever-se-ão demarcar os seus contornos sempre que se aborde este conceito.

Assim, e nesta perspetiva, em nossa opinião Portugal não foge à regra sendo, pela razão enuncia$\mathrm{da}$, esta matéria lecionada e diversa formas em diversas disciplinas e nos mais variados cursos espalhados pelo país. Deste modo, podemos verificar que o tema da gestão da informação se encontra representado em diversos planos de estudos sob diversas designações, entre as quais poderíamos mencionar, a título de exemplo: Gestão da informação em Arquivo, Gestão da informação em Bibliotecas, Gestão da informação nas organizações, Gestão e tecnologias da informação, Gestão e organização e serviços de informação, entre outras. Neste sentido, qual seria o ponto em comum em todas estas designações? A nosso ver seria a necessidade do uso de um qualificador para fixar a aceção sob a qual este conceito está a ser considerado. Daí deriva que a gestão da informação, enquanto matéria de ensino a ser lecionada em Portugal, o é, efetivamente, comungando deste tipo de condicionamentos que fazem com que a sua abordagem apareça representada nos currículos fazendo-se acompanhar dos qualificadores próprios que lhe restringem a amplitude do significado.

De qualquer modo, e tendo em vista responder à questão em epígrafe, poderíamos ainda referir que a estruturação do ensino da Gestão da Informação em Portugal, de forma semelhante ao que ocorre no Brasil, aparece vinculada tanto ao currículo de algumas das principais licenciaturas disponíveis no país quanto ao nível dos mestrados e dos doutoramentos. Naturalmente, nestas duas últimas vertentes opta-se por uma abordagem menos generalista e mais especialista e focalizada do tema, de forma a conectá-lo com as questões de fundo da investigação em Ciência da Informação na realidade atual e com os diversos imperativos do mercado de trabalho e das tecnologias de informação e da comunicação, das quais a própria área da gestão da informação, pelas mais diversas razões, passa cada vez mais a depender. 


\section{Que universidades/faculdades são destaque na formação de gestores da informação em Portu- gal ou mesmo na Europa? É possível indicar diferenciais?}

Na Europa, como todos nós sabemos, há uma herança e uma tradição muito fortes ligadas à Documentação, que vêm desde Paul Otlet e que se manifestam com mais ênfase nos países mediterrânicos. Esta herança e tradição condicionaram durante décadas, e em certos casos ainda condicionam, o ensino e a formação em Ciência da Informação em Portugal e nos demais países que comungam da mesma realidade. Tendo em linha de conta tanto este aspeto quanto o conteúdo da resposta dada à questão que nos foi colocada anteriormente, é natural que não nos sintamos confortáveis em apontar diretamente uma Escola ligada especificamente à área em Portugal, mas sim referir a existência de um núcleo consistente de Instituições do Ensino Superior público português distribuídas no circuito Porto, Lisboa e Coimbra, em que realmente encontramos excelente formação na área da Ciência da Informação, em geral, e, por extensão, em Gestão da Informação como sua área disciplinar subsidiária, em particular. Este "núcleo duro" de instituições portuguesas já vem acumulando experiência no ensino e na investigação desta matéria, pelo que consideramos que o país, sob este ponto de vista, oferece opções a considerar no circuito internacional, tanto na vertente do ensino quanto da investigação nesta área, na atualidade. Ademais, a experiência e a produção científica portuguesa têm-nos demonstrado que já há um núcleo bastante consistente de conhecimentos e, consequentemente resultados, produzidos nessa área. A título de exemplo, poderíamos mencionar que numa rápida consulta realizada ao Repositório da produção científica portuguesa em acesso aberto (RCAAP), no período considerado entre 2004 e 2014, encontramos cerca de 2813 registos associados à Gestão da informação no âmbito da Ciência da Informação, dado que consideramos ser bastante satisfatório quando comparado com o número de instituições de ensino com cursos na área no país, no período em causa, e também com a extensão do território e da população portuguesa. Embora não possamos precisar em que medida, observamos pela nossa experiência que este quadro se repete, de uma forma geral, pelos demais países europeus que herdaram a matriz da Documentação e que em consequência disso mesmo vêm desenvolvendo programas, planos e projetos virados à gestão da informação muito mais recentemente. Dentro deste panorama, uma ressalva deve ser feita ao caso particular e bastante conhecido da Inglaterra, cujo modelo anglo-saxónico naturalmente dista da realidade mediterrânica por nós realçada.

\section{Como o fenômeno "Big Data” influencia a área de Gestão da Informação?}

Em primeiro lugar, importa definir o que são os big data. Trata-se de um conjunto massivo de dados online que são descobertos, capturados, agregados, geridos e disponibilizados por empresas, para fins de negócio, monitorização de informação e tomada de decisão. Deste ponto de vista, a gestão da informação é uma área profundamente influenciada pela recolha de dados massivos, uma vez que a referida recolha implica, logicamente, a armazenagem dos grandes volumes de dados recolhidos quer de pessoas, quer de organizações, para a sua posterior distribuição e uso para os fins previamente mencionados (negócios, estratégias, tomadas de decisão).
Assim e por um lado partindo-se do sobejamente conhecido pressuposto de que toda a informação pode e deve ser gerida, os big data ou dados massivos não deveriam escapar a esta regra e os/as gestores/as de informação, do presente e do futuro, deveriam aprender regras e estratégias de aproveitamento de mais esta oportunidade oferecida pela evolução das tecnologias de informação em rede. Por outro lado, como se trata de um conceito ainda recente e pouco consensual em diversos aspetos, dever-se-ia tratar o tema com alguma precaução, não deixando escapar aquelas balizas que normalmente nos são fornecidas pela Ética, quer num sentido formal, quer num sentido prático. A nosso ver, por exemplo, seria 
lícito que os dados massivos fossem utilizados como fonte e recurso para a gestão do conhecimento organizacional, no âmbito do que atualmente convencionou-se designar por Inteligência Competitiva, já não sendo igualmente lícito, nem aconselhável por um/a gestor da informação, o seu uso ou apropriação em situações de espionagem, como tem sido denunciado em diversos casos já do domínio público. Do mesmo modo, as questões que se referem à privacidade das pessoas deveriam ser muito bem acauteladas aquando da sua gestão e do seu uso ou reuso. Veja-se, por exemplo, no âmbito da União Europeia, a normativa que recentemente deu direito e margem para que cidadãos/ãs comunitários/as solicitassem à empresa Google que retirasse a sua identidade daquele motor de busca. Naturalmente, a própria empresa tem referido, relativamente a esta imposição, que cada caso (leia-se solicitação recebida de cidadãos/ãs visando a retirada do seu nome das buscas efetuadas pelo respetivo motor) será analisado individualmente. No entanto, sabe-se que embalados/as por esta medida, mais de 40.000 petições desta natureza, vindos de cidadãos/ãs europeus (a medida só contempla os cidadãos/ãs comunitários/as), já terão sido entregues à empresa Google.
Toda essa avalanche terá consequências. Como é bom de ver, esse fenómeno, à semelhança de outras inovações tecnológicas que o precederam, ainda carece de uma ampla discussão na sociedade, acompanhada de uma respetiva regulamentação, que ainda não existe, tanto quanto sabemos, na maioria dos países. O próprio proeminente historiador Melvin Kransberg (1917-1995) e a própria história das tecnologias nos ensinaram, e nos vêm ensinando vezes sem conta, que as próprias tecnologias que criamos não são boas nem más, tão pouco serão neutras, dependendo a sua bondade ou maldade exclusivamente do uso de que delas façamos num dado momento. Tal máxima, a nosso ver, aplica-se muito bem ao caso dos dados massivos, que se por um lado se apresentam como uma franca zona de oportunidade para as organizações e os/as gestores/as de grandes volumes de informação pelas potencialidades que o seu uso, gestão e manejo evidentemente representam, por outro, no vazio que precede à sua necessária regulamentação, podem representar uma séria ameaça aos direitos e à privacidade dos cidadãos/ãs, sendo este um Bem Maior que todo/a e qualquer profissional de informação, gestor/a ou não, no respeito aos preceitos ditados pelos respetivos códigos de ética e de deontologia profissional deveria esforçar-se por assegurar.

\section{Que relações podem ser estabelecidas entre a Gestão da Informação e a gestão/governança de dados?}

Para dar resposta a esta interrogação, nunca é demais recordar que a gestão abarca quatro facetas: organização, planeamento, controlo e direção; de onde se propugna por uma necessidade de articulação de toda e qualquer política de Governança de dados com estas quatro facetas tão peculiares ao ato de gerir. Ademais, se assumimos que no conceito de Governança se encontra o exercício do poder e se temos como pressuposto que informação é poder, logo não apenas está clara como também perfeitamente estabelecida a relação entre estas duas variáveis: sem informação não se exerce o poder, isto é, não se exerce a boa Governança. Mas, como é bom de ver, na atualidade, o conceito de informação, sobretudo nos meandros da Governação, deve associar-se aos conceitos de transparência e de prestação ou rendição de contas ou responsabilidade social (accountability, na terminologia original). Por tudo isso e pelo que ainda se infere da resposta à questão anterior (referente aos dados massivos e ao seu uso na, e pela, gestão da informação), podemos inferir, e com uma boa margem de certeza, que sem gestão da informação não há Governança de dados e sem politicas assertivas de gestão da informação tanto menos se tem o controlo dos dados e evidentemente da informação que possuímos e que pretendemos distribuir, utilizar e reutilizar a bem dos/as cidadãos/ãs e da Governança na, e da, própria sociedade. 


\section{Qual o atual estágio de desenvolvimento das pesquisas na área de Gestão da Informação em Portugal?}

Tal como foi referido em resposta à questão $\mathrm{n}^{\circ} 2$, esta área encontra-se francamente em expansão, todavia e a nosso parecer de uma forma ainda não totalmente consensual, equilibrada e consolidada, nos diversos cursos e ciclos de estudos oferecidos no País. Do nosso ponto de vista, a polissemia do termo e a sua consequente utilização em diversas áreas e aceções, e aqui nos reportarmos à resposta dada à questão $n^{\circ} 1$, são em boa medida variáveis intervenientes nesse processo. Não obstante as dificuldades e a vicissitudes sofridas, entre elas a forte herança recebida da Documentação e das suas tradições, também apontadas anteriormen- te por nós, já é possível observar a existência de um corpo consistente de produção científica na área em Portugal (veja-se a este respeito os dados apresentados na mesma resposta dada à questão $\mathrm{n}^{\circ} 2$ ), o mesmo acontecendo ao desenvolvimento disciplinar, circunstância que se pode apreciar pelo aumento substantivo do número de ofertas verificadas nos diversos cursos de Ciência da Informação disponíveis em Portugal, situação que se pode apreciar ao consultar os próprios planos de estudos divulgados em linha pelas diversas Instituições do Ensino Superior português que oferecem cursos desta natureza.

\section{Quais áreas podem ser consideradas “estruturantes” da Gestão da Informação? E por quê?}

Entre outras áreas, pela sua afinidade de propósitos, entendemos que as matérias que se podem considerar como eixos estruturantes são todas aquelas relacionadas com a organização da informação e do conhecimento, pois a gestão pressupõe a organização (sendo esta, como dissemos anteriormente, uma das suas quatro facetas). Assim, todas as disciplinas que tenham que ver diretamente com a representação de conteúdos e/ ou informação estariam incluídas nesta relação. Naturalmente, e no mundo atual, não poderíamos deixar de considerar como muito positiva a aquisição de competências relacionadas com o franco domínio das Tecnologias de Informação e Comunicação, nomeadamente no que concerne ao manuseamento e à monitorização de aplicações e de plataformas digitais. Convém recordar que muitas das tarefas de gestão da informação que se fazem hoje dependem do exercício destas e de outras habilidades e competências, entre as quais ainda poderíamos citar e a título de exemplo, dada a sua relação direta com o caso da gestão e do uso particular dos dados massivos, o domínio de ferramentas próprias da Estatística e da análise de dados.

\section{Como a atual crise econômica tem afetado a inserção de gestores da informação no mercado de trabalho português e europeu?}

De facto a crise reflete-se, por exemplo, na psicologia do consumo, o que concorre em grande medida para a retração dos mercados nas suas diversas manifestações. Não obstante, a própria etimologia da palavra crise descortina um outro universo que é o das opções. Neste sentido, a crise constituiu-se num motor impulsionador para as novas oportunidades e para aquela tão necessária como fundamental articulação entre a Universidade e o mundo do mercado de trabalho. Nesse sentido, regista-se que a universidade portuguesa tem tentado auscultar mais a sociedade, perceber mais as suas necessidades e adaptar-se mais e melhor a essas novas realidades descortinadas pela crise (emprego volátil, emprego sazonal, emprego qualificado, desemprego jovem, etc.). É neste contexto, que a universidade portuguesa tem tentado procurar assumir-se num papel não apenas de ouvidora como também de mediadora entre estas duas realidades. Neste sentido, e em diversas intervenções (estágios, conferências, congressos, workshops, projetos, ações de formação, etc.) temos visto e testemunhado, por todo o país, que os/as responsáveis e os/as cola- 
boradores em cursos de Ciência da Informação têm procurado ampliar o seu raio de ação para as organizações lucrativas e não lucrativas, de modo a tentar, agora mais do que antes, explicar o papel estratégico que quer pela formação, quer pela vocação, os/as gestores/as de informação poderão e deverão ocupar ao nível organizacional ao potenciar soluções para a própria crise com ações e intervenções locais, sensibilizando e captando a sua atenção para a relevância desta questão.

\section{Que aspetos podem ser priorizados na formação de gestores de informação para enfrentar os desafios trazidos por tal tipo de crise?}

Por tudo quanto foi dito nas questões anteriores, julgamos que dar cada vez mais formação adequada às necessidades e às exigências do mercado de trabalho, sem descurar os conhecimentos de base e os fundamentos que definem a área, sempre necessários ao exercício competente da profissão, são uma excelente alternativa. Tal como referimos na resposta dada à questão $\mathrm{n}^{\circ} 7$, é preciso auscultar a sociedade e o mercado, no sentido de perceber as suas necessidades. Neste sentido, conforme também afirmamos, as estratégias de aproximação entre a empresa e a Universidade são fundamentais e bem-vindas, principalmente em momentos de crise como os que temos presenciado na conjuntura da Europa atual. Todavia, não nos podemos esquecer de que as crises fazem parte da própria estrutura capitalista e que, em função disso, temos de aprender a lidar com elas. Especialmente em conjunturas tais como esta em que atualmente vivemos, somos confrontados com a necessidade de investir no perfil humanís- tico dos/as nossos/as alunos/as, fornecendo-lhes uma formação que lhes permita perceber-se e situar-se de uma forma mais abrangente na sociedade, para além naturalmente da necessidade de investir na sua alta capacitação técnica e científica e no conceito de aprendizagem ao longo da vida, tão caro à realidade tecnológica contemporânea. É no seio destas tão difíceis quanto particulares e estimulantes conjunturas que temos aprendido a perceber cada vez mais, e com mais intensidade, o verdadeiro valor daquilo a que designamos por formação ampla, que contempla, ou deve contemplar, tanto o ponto de vista profissional quanto a investigação e a ação interventiva aluno/a enquanto ator/a social, agente da mudança e cidadão/ã. Neste sentido, acreditamos que apesar dos esforços contrários a Universidade portuguesa tem procurado repensar, nos seus diversos fóruns para debate, o seu papel de formadora de recursos humanos capazes de lidar com a complexidade da atual realidade. 


\section{Information Management in Portugal: education \& employment conditions and some prospects}

\begin{abstract}
The Professors Cristina Freitas and Maria da Graça Simões answer questions prepared by teachers from the Faculdade de Informação e Comunicação (Gestão da Informação Undergraduate Degree) da Universidade Federal de Goiás UFG. The questions are related to the educational structure dedicated to the issues of information management in Portugal, the influence of the "Big Data" phenomenon on education and training in the area - including discussions on data governance, the fundation areas of Information Management and the main approaches to information research in the Country. Besides, they discuss the employment conditions (threats and opportunities) for professionals in Information Management in Portugal and in Europe [Available Language: Portuguese/Portugal].
\end{abstract}

\section{Keywords}

Information Management. Job market. Professional training.

Maria Cristina Vieira de Freitas é Professora Auxiliar Convidada na Universidade de Coimbra, membro associado da BAD (da qual também é revisora dos Cadernos BAD) e da SOPCOM. Tem Doutorado em Biblioteconomia e Documentação pela Universidade de Salamanca, Mestrado em Ciência da Informação pela

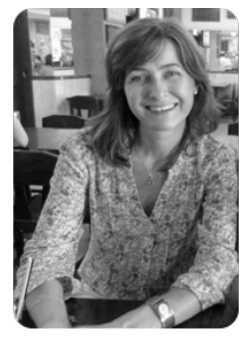
Universidade Federal de Minas Gerais, Especialização em Conservação de Obras sobre Papel pela Universidade Federal do Paraná. É Licenciada em Documentação e Arquivística pela Universidade de Aveiro e em História pela Faculdade de Filosofia, Ciências e Letras de Cataguases. É membro do Conselho de Redação do Boletim do Arquivo da Universidade de Coimbra, e dos centros de investigação CIDEHUS (Universidade de Évora) e CONDOR (Universidad de León). Autora e/ou coautora em dezenas de publicações científicas em veículos nacionais e internacionais. Interessa-se pelas seguintes linhas de investigação: organização, gestão e preservação da informação e do conhecimento em arquivos; arquivos digitais; metodologia da investigação científica; análise qualitativa de dados com o apoio de software.
Maria da Graça de Melo Simões, é Professora Auxiliar da Faculdade de Letras da Universidade de Coimbra, no Curso de Ciência da Informação Arquivística e Biblioteconómica, onde leciona disciplinas relacionadas com a Organização do conhecimento. Tem Doutorado em Ciência da Informação pela Universida-

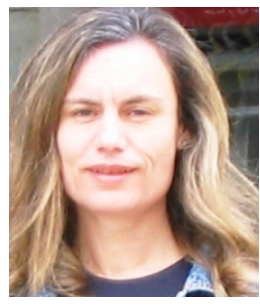
de de Salamanca, Mestrado em Ciência da Informação pela Faculdade de Letras da Universidade de Coimbra, Pós Graduação em Ciências Documentais pela Faculdade de Letras da Universidade de Coimbra, Pós Graduação em Estudos Europeus pela Faculdade de Direito da Universidade de Coimbra e Licenciatura em História pela mesma Universidade. É autora de diversas monografias e artigos publicados em revistas nacionais e internacionais especialmente sobre temas relativos à Representação da Informação e Organização do Conhecimento.

\section{Agradecimentos}

A Equipe Editorial da AtoZ agradece às entrevistadas e aos seguintes entrevistadores do Curso de Gestão da Informação da Universidade Federal de Goiás (UFG): Prof. Dr. Dalton Martins; Prof. Dr. Alexandre Ribeiro Afonso; Prof. Ms. Arnaldo Alves Ferreira Júnior; Prof. Ms. Rubem Borges Teixeira Ramos; Profa. Dra. Eliany Alvarenga de Araújo.

Como citar este documento:

FREITAS, M. C. V. de; SIMÕES, M. G. M. Gestão da Informação em Portugal: formação, mercado e perspectivas. AtoZ: novas práticas em informação e conhecimento, Curitiba, v. 3, n. 1, p. 6-11, jan./jun. 2014. Disponível em: <http://www.atoz.ufpr.br>. Acesso em: . Entrevista. 